\title{
HOMBRE Y NATURALEZA EN EL PENSAMIENTO MEDIEVAL (Congreso Internacional de Filosofía Medieval, VII Latinoamericano. Buenos Aires, 12-15 Octubre, 1999).
}

Sorprendentemente para los que íbamos llegando de este lado del Atlántico al Congreso Internacional de Filosofía Medieval, VII Latinoamericano, 12 al 15 de Octubre de 1999, y que nos habíamos reunido en el areopuerto(Gatwick) de Londres con bajas temperaturas, en Buenos Aires era primavera.

Eran los buenos aires de la primavera los que se respiraban en la ciudad porteña y los que en el acogedor convento franciscano de San Antonio de Padua, sede del Congreso, se fueron haciendo más intensos y perfumados. Aires de primavera, filosofía medieval y un convento franciscano. Sentirse en casa, en la paz de un mundo ordenado, ajustado: hospedería, refectorio, capilla, sala capitular, claustros, aulas, biblioteca, librería..., huerta, jardines, naturaleza florecida, cantos de los pájaros..., toque de campana. Hombre y naturaleza en el Pensamiento Medieval, ${ }^{1}$ un tema, un marco y un tiempo apropiados para un gran Congreso.

Saludos, encuentros de ya viejos colegas en pasados congresos, Lovaina, Helsinki, Ottawa, Erfurt, de la Société Internationale pou l'Étude de la Philosophie Médiévale (SIEPM), y ahora, auspiciado por dicha Sociedad, en el Internacional de Buenos Aires, también, con muchísimos otros nuevos de Argentina, Brasil, Colombia, Chile, México, Perú, Venezuela, amén de Alemania, Bélgica, Croacia, España, Gran Bretaña, Italia, Portugal..., con adhesiones de los más diversos lugares del mundo, Canadá, Estados Unidos, Japón, Filipinas, Francia...

Todo estaba ya preparado. Los esfuerzos y callada labor llevada a cabo desde el Congreso de Erfurt (Alemania), 1997, por los que habían asumido la responsabilidad de organizar este Congreso, el Grupo Argentino de Filosofía Medieval y el Instituto Teológico Franciscano «Fray Luis de Bolaños», con la colaboración intensísima y generosa de la Comisión Brasilera de Filosofía Medieval, tenían que tornarse, ahora, en abundantes frutos. Al frente de la Comisión Ejecutiva Argentina se encontraban Celina Ana Lértora Mendoza, Jorge Alberto Bender y Claudio Marcelo Conforti. Y de la Comisión Científica, Francisco Bertelloni(Argentina), Silvia Magnavacca (Argentina), Luis Alberto De Boni (Brasil), Jorge M. Ayala (España), Antonio Merino (Italia) y Gregorio Piaia (Italia). En la Secretaría estaban María Pilar Alfaro y Hortensia Bover Pigrau. Y en representación de la SIEPM, se hallaban el presidente de honor, Albert Zimmermann, el presidente, David Luscombe y la secretaria, Jacqueline Hamesse.

El Congreso se inauguraba solemnemente en la gran Sala Capitular del convento en la tarde del 12 de Octubre, era día, también, de fiesta grande en Argentina, era el día de la Hispanidad. Bellas melodías del Coro Santa Clara, palabras de bienvenida del Provincial de los Franciscanos, Norberto R. Buján; discurso de apertura del Prior del Convento de San Antonio de Padua, Jorge Bender; bienvenida del Grupo Argentino de Filosofía Medieval, por Francisco Bertelloni; mensaje de la SIEPM a cargo de Albert Zimmermann, y presentación del Congreso por Celina A. Lértora Mendoza.

Las lecciones académicas corrieron a cargo de David Luscombe, Peter Abelarde and the Creation of the World y de Jacqueline Hamesse, La rélation à la nature dans la pensée franciscaine pendant le 13è siècle, dejando planteado el tema del hombre y de la naturaleza en el pensamiento medieval. D. Luscombe estableció una panorámica en la evolución de los estudios desde el Tercer Congreso Internacional de Filosofía Medieval en Passo della Mendola, en 1964, en el cual, también, se abordó La filosofía de la naturaleza en la Edad Media, hasta el presente Congreso, y señaló el descubrimiento de la naturaleza que se fue haciendo, buscando un equi-

1 El volumen primero de las Actas del Congreso ya ha sido publicado, Hombre y Naturaleza en el Pensamiento Medieval, Veritas, 3 (1999) 497-936. El volumen segundo lo hará en la primavera de 2000. 
librio, tal como aparece en el comentario al relato de la creación de la Expositio ad Hexaemeron de Pedro Abelardo, entre la obra de la voluntas Dei y el poder de la vis naturae y la vis insita in rebus, que Dios insertó en la creación. Por su parte, J. Hamesse, destacó en este contexto la importancia que la naturaleza tuvo en la orden franciscana desde sus primeros momentos con San Francisco de Asís, viendo avalado ya este hecho, entre otros, en la mayor parte de sermones de San Antonio de Padua y en toda la terminología técnica que iría elaborando la Escuela Franciscana para el estudio de la naturaleza, destacando en este sentido a San Buenaventura.

Esta búsqueda de equilibrio, entre voluntas y vis, y redescubrimiento del hombre y de la naturaleza sería la perspectiva que iba a estar presente en todo el Congreso a través de sus distintas sesiones temáticas. Inclusive, quizá, se pudiera decir que haya sido su nota más característica, un ejercicio de discernimiento en torno al hombre, la naturaleza y Dios, en muchos casos volviendo los ojos al relato de la creación, en toda la riqueza de matices, conceptualizaciones y consecuencias que parecen presentarse, a la par que un desvelamiento de las raíces medievales del pensamiento moderno.

El Congreso ya estaba iniciado. Y había comenzado con un comentario al relato de la creación, principio de otros muchos relatos y comentarios que se irían haciendo a dicho relato (Gén. 1-3). Y así, la primera tardenoche se fue dejando sentir en las vidrieras de la gran Sala Capitular en la que estábamos. El ocaso cerraba esta sesión inaugural. Por los claustros, sin prisa y con muchas ideas que comunicar y contrastar, nos fuimos al conventual refectorio de estructura medieval, un espacio abierto donde todos nos hacíamos presentes, en igualdad de presencia, con la palabra de la mirada. Fuera, la naturaleza cobraba nueva vida en medio del cielo austral de brillantes estrellas.

Al día siguiente, el despertar de la naturaleza y el insistente canto del teruteru en los jardines del convento congregaba, a primera hora, en el refectorio a los profesores Luscombe, Zimmermann, Hamesse, Ramón Guerrero, Fuertes Herreros, Piaia, De Boni, Lupi, Fortuny, C. R. de Souza y Celina A. Lértora..., en torno a la variada fruta como traída del Edén, el café, los dulces y el delicado manjar junto con los tiernos panecillos. Eran los más madrugadores y lo serían en días sucesivos. Con el miércoles 13, comenzaban las sesiones temáticas, informes de investigación y talleres, con exposición y debate de los trabajos, en las aulas Roberto Grosseteste, San Buenaventura, Roger Bacon y Duns Scoto, y se prolongarían hasta el viernes 15, desarrollando aspectos concretos de la temática general. A las nueve, el inconfundible sonido de la campana se extendía por todos los claustros y avisaba que se iniciaban las sesiones, y los cerca de 3.00 congresistas se repartían por las distintas aulas.

\section{SESIONES TEMÁTICAS:}

Las sesiones temáticas casi todas ellas, de una u otra manera, iban a girar en torno al descubrimiento del hombre y de la naturaleza que se fue haciendo en el pensamiento medieval. Muchísimas referencias al hombre como ser y ente creado, «secundus deus», microcosmos, dignidad del hombre, cuerpo-alma, espíritu, mente, razón, voluntad, conocimiento, verdad, contingencia, muerte, felicidad, libertad, ley. A la naturaleza, creación, materia, caos, cosmos, mundo, física, espacio, tiempo, causa, teleología, necesidad-contingencia. Muchas alusiones, casi constantes, al relato de la creación y, también, a los relatos de viajes. Presencia muy significativa del tema de los saberes y de su ordenación, así como de la ciencia, del método y de las enciclopedias.Y un lugar muy destacado para el pensamiento islámico; también para la ética, la filosofía política y la historia. Y cuatro núcleos, que supieron aglutinar bastantes trabajos: San Agustín, Santo Tomás, Escuela Franciscana y Nicolás de Cusa.

Señalo las distintas sesiones y los trabajos a ellas presentados. La metodología era la empleada en los congresos de la SIEPM: exposición del trabajo y debate del mismo, quizá esto último, como siempre, lo más enriquecedor.

\section{SAN AGUSTÍN}

Se dedicaron dos sesiones a San Agustín. La primera con la exposición y debate de los trabajos de Raquél Da Silva Rodrigues, Liberdade: Sto. Agostino \& Kant; de Sonia Maciel, Eudamonia em Platâo Agostinho - 
Uma tentativa de aproximaçâo; y de Marcos Nunes Costa, Crítica Agostiniana à Negatividade Material no Maniqueísmo e no Neoplatonismo.

Y la segunda, Cristian Tavitian, Consideraciones metafisicas de la persona en San Agustín; de Regis Coimbra, O paradoxo do livre arbítrio em Santo Agostinho; y de Ricardo M. García, «Magis esse» y «minus esse» en San Agustín y una posible influencia neoplatónica.

\section{ORGANIZACIÓN DEL SABER NATURAL}

Exposición y debate de los trabajos de Miguel de Asúa, El De arte venandi cum avibus de Federico II; de José Luis Fuertes Herreros, Paraíso y Edad de Oro como saber y método genealógico en los inicios del Renacimiento; y de Carlos A. R. do Nascimiento, O descompromisso ontológico da ciência moderna e suas raizes medievais.

\section{CIENCIA, ALQUIMIA Y MAGIA}

Esta sesión corrió a cargo de Jaime Bortz / Claudia Sedlinsky, Maimónides (1138-1204): sobre el agua y su relación con la vida; de Silvia Magnavacca, Contemplación de lo natural y acción humana en la magia: San Agustín y Pico della Mirandola; y de Rafael Ramón Guerrero, La alquimia en el Islam. ¿Transformación de la naturaleza o transformación del hombre?

\section{4. ÉTICA Y FILOSOFÍA POLÍTICA}

Se expusieron los trabajos de Carlos Rodrigues Gesualdi, La unidad temática de la Ética Nicomaquea: dificultades de su recepción en el siglo XIII; de Sergio R. Strefling, A soberania da lei humana em Marsílio de Pádua; y de Jorge M. Ayala, Antecedentes medievales de los Derechos Humanos.

\section{ANTROPOLOGÍA}

Dos sesiones se dedicaron a este tema con exposición y debate de los trabajos, en una primera, de Mario S. de Carvalho, Homem e natureza em Henrique de Gand: uma mudança de rumo na antropologia augustinista; Lênia M. Mongelli, Homem e natureza na literatura medieval: as forças irracionais; y de José Ignacio Saranyana / Francisco Cardona, Sobre lo imaginario femenino bajomedieval. Ramón Llull vs. Francesc Eiximenis.

Y en la segunda, los de Giannina Burlando, Teleología Antropocentríca: desde el estoicismo a la escolástica; de Enrique Corti, La razón humana y la naturaleza divina dialéctica (Ed. "De incarnatione Verbi» de San Anselmo); y de Eduardo Briancesco, Eckhart ¿contemptus mundi o liberación de la humanidad?

\section{METAFÍSICA}

Participaron en esta sesión, Silvana Filippi, Eckhart, la doctrina de la analogía y el anonadamiento posmoderno de lo real; Elisabeth Reinhardt, La condición del ser humano, segín la Summa Sententiarum de Odón de Lucca; Joaquim Cerqueira Gonçalves, Ser, natureza e história. Uma exortaçâo medieval à manifestaçâo da realidade; y Manoel Vasconcelos, $A$ trindade no Monológio de Anselmo de Aosta. 


\section{NICOLÁS DE CUSA}

Se expusieron los trabajos de Claudia D’Amico, El hombre como «secundus deus»: forma única y reconstrucción nocional de géneros y especies en el pensamiento cusano; de Jorge M. Machetta, Nicolás de Cusa: perspectivas éticas a partir de su concepción del individuo y de la visión de Dios; y de Joâo M. André, Homem e Natureza em Nicolau de Cusa: O microcosmo numa perspectiva dinâmica e criadora.

\section{PENSAMIENTO FRANCISCANO}

Se dedicaron tres sesiones. La primera con la exposición y debate de los trabajos de Claudio Conforti, Hombre y naturaleza en la Summa de Alejandro de Hales; de Celina A. Lértora Mendoza, Hombre y naturaleza en el Hexaemeron de Grosseteste; y de Hermes Puyau, Duns Scoto, el argumento ontológico y la contingencia.

La segunda, con Luis A. De Boni, A noçâo de homem em Duns Scotus; Roberto F. Cazzasa, Voluntad y naturaleza según Duns Scoto; y Pedro Leite, Guilherme de Ockham: Notitia intuitiva como fundamento do conhecimiento humano.

Y la tercera, con Esteve Jaulent, O conceito de natureza em Lúlio e sua aplicaçâo ao ser humano; José Antônio de C. R .de Souza, O Programa Ético de Santo Antônio para o Clero Regular; Horacio Botalla, Espacio y representación en la Chronica de Fray Salimbene de Adam.

\section{FÍSICA}

Se expusieron en esta sesión los trabajos de Francisco José Fortuny Bonet, La física de Aristóteles y las físicas «aristotélicas» de Ockham; de Antonio Pérez Estévez, La materia prima como fundamento de la naturaleza en la Edad Media (Tres lecturas de la hyle aristotélica); y de Bartomeu Forteza Pujol, La physica en los aristotélicos del siglo XVI.

\section{PATRÍSTICA}

Participaron, Joâo Lupi, O homem e o mundo na Antropologia Teológica de Orígenes; José M. da Cruz Pontes, La defensa del valor de la razón humana en la patrística pre-agustiniana y su culminar en Agustín; Reinholdo Ullmann, Plotino - a relaçâo entre o uno e o mundo; y Jan ter Reegen, O homem no Liber de Causis.

\section{SANTO TOMÁS}

Dos sesiones se dedicaron a Santo Tomás. La primera con la participación de Angel Salvador Astolfo, Acerca del cuerpo y de la delectación sensible en algunos textos de la Primera Parte de la Suma de Teología; de Patricia Moya Cañás, Cuestiones acerca de la explicación tomasiana del alma intelectiva como forma del cuerpo; y de Ana Mallea, «Nuestros hermanos menores» y Santo Tomás.

Y la segunda, Jörg Alejandro Tellkamp, Tomás de Aquino: sobre la naturaleza de lo mental; José Ricardo Pierpauli, El significado del concepto de Equidad en las obras de Alberto Magno y Tomás de Aquino; Julio A. Castello Dubra, Hombre y Naturaleza en Tomás de Aquino; y de Scott Randall Paine, Love as the summit of immanent activity and man's relationship to nature in the thought of Thomas Aquinas. 


\section{EPISTEMOLOGÍA}

Se presentaron los trabajos de Jorge Bilbao, El conocimiento científico de los escolásticos a la luz de la ciencia moderna; de Miguel A. García Jaramillo, El esquematismo aviceniano; de Rodolfo E. D’Andrea, La verdad matemática en tiempos de caballería; y de Héctor Manuel Sarmiento Gordillo, El problema del conocimiento en los procesos educativos del medioevo.

\section{FILOSOFÍA POLÍTICA}

Exposición y debate de los trabajos de Luis E. Bacigalupo, Sobre los tres modos del derecho natural en Ockham; de Francisco Bertelloni, El locus «homo microcosmos» en la literatura política: Egidio Romano y Dante Alighieri; de Antonio Tursi, Naturaleza e historia en el Tractatus de Juan de París; y de Angel Muñoz García, Naturalmente libres, naturalmente esclavos.

\section{INFORMES DE INVESTIGACIÓN}

Se dedicaron dos sesiones a informes de investigación. La primera, a cargo de Jorge Oscar Velázquez Gallardo, La concepción agustiniana del hombre a la luz del hallazgo de Dios. Y la segunda, con la participación de Carolina A. Montoya Vargas, El tratado de la ley natural en Francisco Suárez y en Santo Tomás de Aquino, y de Carolina J. Fernández, Ockham y el problema de la causalidad.

\section{TALLERES}

Se desarrollaron dos modalidades de talleres: Taller didáctico y Taller de reflexión.

\section{a) Taller didáctico:}

Lo presentó Alfredo Culleton, La filosofía medieval en la Internet: potencialidades y aprovechamiento. Este taller despertó verdadero interés entre los congresistas. Se realizó en la tarde del primer día del Congreso, y durante todo el Congreso se estuvieron haciendo prácticas en los distintos ordenadores que al efecto había.

De otro lado, y en sesión distinta, también se abordó a cargo de Jorge Seibold, ¿Cómo enseñar filosofía de la naturaleza?

\section{b) Taller de reflexión:}

Participaron en él, Joaquín Cardoso Duarte, Nicolas de Cues: la vision qui parle ou les icônes; José M. Nieva, Hacia una re-lectura franciscana de nuestro mundo; de María L. Sirgado Ganho, La actualidad de San Antonio de Lisboa y de Padua: la dialéctica del amor a la naturaleza, al hombre y a Dios; y de Guillermo Termenón y Solís, O homem moderno e sua origem medieval.

\section{PRESENTACIÓN DE LIBROS}

En el teatro San Francisco se presentaron por parte de Celina A. Lértora el volumen primero de las Actas del Congreso, Hombre y naturaleza en el Pensamiento Medieval, Veritas, 3 (1999) 497-936, «dando las gra- 
cias a la dirección de la revista Veritas, al profesor Luis A. De Boni y las autoridades de la Pontificia Universidade Católica do Rio Grande do Sul (Porto Alegre, Brasil) por su activa colaboración en la publicación de este primer volumen de las Actas del Congreso», y señalando que el volumen segundo de las Actas estaría publicado para la primavera del 2000.

Asímismo se presentaron los libros de Celina A. Lértora Mendoza, El legado de Sefarad por Francisco Bertelloni. De Lênia Márcia Mongelli (org.), Trivium e Quatrivium por Luis A. De Boni. De Silvia Magnavacca, Giovanni Pico della Mirandola por Claudia D’Amico. De Josep I. Saranyana, Historia de la Filosofía Medieval por Celina A. Lertora. De Jorge M. Machetta-Claudia D’Amico, Nicolás de Cusa, Un ignorante discurre acerca de la sabiduría (Idiota. De sapientia) por Silvia Magnavacca. De Antonio PérezEstévez, La materia: de Avicena a la Escuela Franciscana por José Luis Fuertes Herreros.

\section{PARA EL GRATO RECUERDO DEL CONGRESO}

Este Congreso Internacional como los otros de Filosofía Medieval no podía olvidar aquellos elementos que ayudan a enriquecer el propio Congreso y a dejar, además, un grato recuerdo en los participantes. Y esto fue ampliamente conseguido.

Se alcanzó sabiéndole imprimir unidad vital e intelectual. Se hizo de la sede un lugar que favorecía el encuentro y el diálogo entre los congresistas, e inclusive el reposo. ¡Cuanta paz y tranquilidad se respiraba en él! El espacio físico, el propio convento, ayudaba a ello. Traspasada la verja y puerta de entrada, se detenía el tiempo. Era lugar de presencia y encuentro filosófico. Los jardines, los claustros, las aulas, las pausas entre las sesiones, el gratis de los cafés durante las 24 horas del día, la sala «convivium», el refectorio..., todo invitaba a ello. La sala «convivium», sobre todo después de la cena, era el lugar de la noticia, de la charla, del diálogo y debate filosófico sobre el estado de la filosofía en Latinoamérica, sobre líneas de investigación, o sobre la situación de las Facultades de Filosofía y de la Filosofía Medieval. ¡Cuantas alegrías y sonrojos viéndonos en el espejo de otros!

Pero, también, y de un modo especial, ayudó a la creación de este ambiente de encuentro y de diálogo entre los congresistas las cenas y las actuaciones que se sucedieron en el espacioso refectorio medieval, y que ahora, para regocijo de unos y envidia de otros, paso a relatar.

El miércoles 13 nos vimos sorprendidos con una cena medieval. Esta constaba de dos partes que se sucedían a la par en el conventual refectorio. De una parte, el maestro cocinera Fr. Pablo Sorrentino supo preparar la espléndida cena, consistente en «sopa de mejillones» según receta de Le Ménagier de Paris (s. XIV), «venado al agridulce» según Libro de Arte Coquinaria del Maestro Martino (s. XIV) y «sopas de nata» recogida por Martínez Montiño (s. XVII). Y para los lectores, que no asistieron al Congreso, les proporciono la receta de la sopa de mejillones, o la que podía ser también de ostras, tal como sugería Le Ménagier de Paris: «Tome pan tostado sobre parrilla, y ponga a remojar en puré; y ponga el pan, vinagre y verjus y vino, canela la que más y jenjibre, y poco de especias pequeñas, y mézclelo todo junto; y a hervir cebollas fritas y azafrán y hacerlas hervir bien; y cuando está cocido, póngalo en una vasija de tierra, y fría las ostras o los mejillones, y póngalos a hervir con la sopa».

Y de otra parte, asistíamos a la Representación del Nacimiento de Nuestro Señor de Gómez Manrique (s. $\mathrm{XV}$ ) por un grupo de Hermanos del Instituto Teológico Franciscano «Fray Luis de Bolaños» y al Concierto de Música Medieval a cargo de la Agrupación Musical «Hieronimus Kessier» con Música instrumental del s. XIII, Música del camino de Santiago de Compostela del s. XIII y Cantigas en honor a Santa María y Nuestro Señor Jesucristo de Alfonso el Sabio, s. XIII. Además de voces bellísmas, entre los instrumentos pudimos escuchar: flautas dulces tenor, alto, contralto y soprano, cromornos tenor y bajo, mandolina, tromba marina, ud, fídula, rabel y chirimías.

El jueves 14, hubo cena antigua del Buenos Aires antiguo. Esta cena, también, tenía dos partes, que se sucedían a la par. La primera, a cargo del maestro cocinero Fr. Pablo que supo nuevamente pasar del papel a los fogones las recetas bonaerenses de mediados del XIX, en este caso, de La cocina ecléctica de Juana Manuela Gorriti, con «sopa de abril», «pastel federal» y «espuma de mar». Como segunda parte, este ambiente del Buenos Aires de mediados del XIX se vió completado y recreado con la representación de «Danza en 
un salón antiguo» con Cuadro de Salón, «De los tiempos de antes» por el Conjunto Coreográfico «El Giro» del Insituto Nacional Superior del Profesorado de Folklore.

La cena del viernes 15, como acto de despedida, fue una cena criolla. Tras ver como se hacía para todos los congresistas la inmensa parrillada con chorizos, morcillas, achuras y carne, pasamos al refectorio a saborear tan exquisitos asados junto con ensalada, chimichurri y copa helada. A la par, los hermanos Dante Ríos y Federico Sánchez nos ofrecían una guitarreada, y nuevamente el Conjunto Coreográfico «El Giro» ponían en escena una «Noche de danza» con Cuadro paisano moderno y Cuadro ciudadano-tango. El tango era el punto final a esta cena de despedida, la llamada a la nostalgia y al recuerdo de Buenos Aires y del Congreso Internacional de Filosofía Medieval.

\section{SESIÓN FINAL Y ACTO DE CLAUSURA}

La tarde-noche del viernes fue una de las más intensas. La sesión final y acto de clausura estuvo precedida por la reunión de Asociciaciones de Filosofía Medieval con la participación de todos los países que estaban representados en el Congreso, en donde desde la SIEPM se acordó que se potenciaría al máximo la información, ayuda para estancias, intercambios entre profesores y universidades, proyectos de investigación, becas, congresos, apoyando, también, para mejor conseguir estos fines la creación de una página en Internet.

Después vino la sesión de clausura con las lecciones de A. Zimmermann, Mort et nature humaine selon l'approche de penseurs médiévaux, y de G. Piaia, Fra contemplazione e dominio. Note in margine al rapporto uomo-natura nel pensiero medievale.

El acto de clausura corrió a cargo de Celina A. Lértora con el informe final en donde señaló el florecer de la Filosofía Medieval y el interés creciente en toda Latinoamérica, así como en Estados Unidos y Canadá, la necesidad de crear una eficiente red de comunicación, tal como se había puesto de manifiesto en la reunión de Asociaciones, ${ }^{2}$ y el diálogo creciente y necesario que se impone en el mundo actual entre la filosofía medieval y moderna para una clarificación adecuada del hombre y de la naturaleza.

Tras unas entrañables palabras de despedida de Luis A. De Boni, cerró el acto Jorge Bender. Mientras, el Coro Santa Clara entonaba el Gaudeamus igitur. Y con un fortísimo y prolongado aplauso abandonábamos la Sala Capitular.

Cuando de salida caminábamos por los claustros, de los jardines comenzó a llegar nuevamente el intenso perfume de la primavera. Efectivamente, en Buenos Aires era primavera. Era la primavera florecida de la Filosofía Medieval en su Congreso.

José Luis Fuertes Herreros Universidad de Salamanca

Facultad de Filosofía Campus «Miguel de Unamuno» 37007 Salamanca

2 La Página Web ya está consituida: Red Latinoamericana de Filosofía Medieval. Se accede por http:/www.clacso.edu.ar/ fepai/filosofíamed.htm; o por: http://www.clacso.edu.ar/ fepai/redlatinoamericana.htm. Tiene por objeto dicha página implementar la comunicación entre quienes se dedican a la Filosofía Medieval en América Latina, pero no se excluye a nadie, el único requisito para pertenecer a la Red es la participación activa en ella. Sus secciones son: 1. Información general. Propósitos de la Red. Modalidades de acceso y comunicación. Organización de la página. 2. Proyectos en curso. Lista de trabajos de investigación, publicaciones que se están realizando, con breve descripción de las mismas. 3. Publicaciones recientes. Revistas (con índice). Ediciones y traducciones. Libros y artículos. 4. Intercambio bibliográfico. Se podrá aquí solicitar información sobre la eventual existencia en otro país de bibliografía de difícil acceso. $\mathbf{5}$. Congresos y Jornadas. Información sobre la marcha de reuniones planeadas y de las recientes. Crónicas. 6. Cátedras. Listado de las actuales, eventuales modificaciones. Concursos. Homenajes. 7. Becas. Información sobre las que se ofrecen. en cada país para nacionales y extranjeros. 8. Sugerencias. Se reciben y publican las que sean de interés general. Las más específicas serán giradas a la persona o institución que corresponda.Para simplificar la actualización de la Página se ruega transmitir la información vía e-mail a Celina A. Lértora Mendoza: fepai@clacso.edu.ar. 